\title{
As Cidades do Interior e as Estratégias Ausentes \\ Uma Observação a partir da Cidade da Covilhã
}

Dominges Vaz ${ }^{*}$

\begin{abstract}
$\mathrm{R}$ Resumo: No presente texto realiza-se uma caracterização sucinta do sistema urbano nacional. São evidenciadas as dinâmicas em curso e os principais problemas e as perspectivas de evolução que se colocam. No seguimento é contextualizada a situação dos territórios de baixa densidade do interior do País. Destaca-se o papel das cidades no desenvolvimento regional, a necessidade de uma visão integrada dos problemas e das soluções, e a possibilidade de alargar consensos a agentes e a actores sociais diversificados.
\end{abstract}

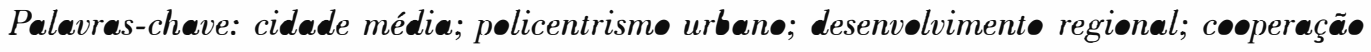
transfronteiriça.

\section{Apresentação}

Neste texto procura-se recensear algumas ideias-chave de como o sistema urbano se organiza no território nacional, relevando as dinâmicas em curso e os problemas e perspectivas de evolução que se colocam, em particular, ao interior do País.

Neste contexto há questionamentos a fazer e que deverão contribuir para o debate em torno de estratégias e projectos congruentes de desenvolvimento regional e urbano dos territórios de baixa densidade do interior.

A capacidade de os poderes locais e regionais liderarem processos de desenvolvimento dependerá, sempre, da possibilidade de alargar consensos a agentes e a actores sociais, bem como, também, de tal exigir alargar a base territorial, envolvendo vários municípios para um mesmo projecto de desenvolvimento local/regional. Não é verdade que a complexidade crescente das cidades exige uma visão integrada dos problemas e das soluções? E que uma visão baseada apenas na circunscrição administrativa se encontra ultrapassada? Não será que as decisões estratégicas já não estão na parte mas sim no todo?

Finaliza-se com uma abordagem que releva os principais desafios com os quais a cidade da
Covilhã está confrontada e cuja gestão determinará o sentido do seu futuro. No centro da reelaboração simbólica desta cidade intervém fortemente a Universidade da Beira Interior, importante actor que está a fazer da Covilhã uma cidade tendencialmente universitária. Tanto em termos da organização intra-urbana como de representatividade exterior, a consolidação e crescente afirmação da Universidade abre as perspectivas para um novo ciclo urbano. Sendo hoje explicitada uma mensagem de acção, pela Autarquia Local, suportada nos vários projectos que protagoniza, de certa forma em analogia com o discurso empresarial da cultura da competitividade, importará esclarecer algumas questões como sejam as seguintes: qual a ideia de cidade subjacente para orientar o ordenamento urbano e a gestão urbanística? E como deverá ser reflectido o papel da Universidade na estruturação dessa ideia? Como conjugar o crescimento da urbanização com a sua qualidade numa óptica de sustentabilidade e integração territorial?

\section{O "Interior" e o Sistema Urbano Nacional}

Da consulta de diversos estudos sobre o sistema urbano nacional, alguns deles de publi-

\footnotetext{
" Docente e investigador, Departamento de Sociologia da Universidade da Beira Interior. Contacto: domingos.vaz@ubi.pt.
} 
cação relativamente recente, importa ter presente algumas ideias-chave que sintetizam perspectivas semelhantes mas nem sempre coincidentes acerca de como o sistema urbano se organiza no país, relevando em particular a situação do interior do território nacional ${ }^{1}$. No seu conjunto estas várias abordagens fornecem uma boa caracterização das dinâmicas em curso e dos problemas e perspectivas de evolução que se colocam². Da sua leitura é, contudo, possível concluir da unanimidade das principais características do sistema urbano que, como tem sido referido, continua a reforçar a litoralização do povoamento ao mesmo tempo que se desenvolve a bipolarização em torno das duas maiores cidades. No interior a população encontra-se concentrada nas poucas cidades existentes, aglomerações de média dimensão (a nível europeu são pequenas cidades) e em alguns aglomerados urbanos ainda de menor dimensão, que se destacam pelo facto de constituírem sedes de concelho ${ }^{3}$.

O estudo de Gaspar e Jensen-Butler (1992) define desde logo que o processo de urbanização contemporâneo em Portugal é tardio face aos outros países europeus e apresenta algumas características muito específicas: elevada concentração da população com origem no meio rural em dois grandes centros, Lisboa e Porto; urbanização da população por via da emigração que é, ao mesmo tempo, um factor retardador do desenvolvimento dos pequenos centros urbanos; e um processo actual de urbanização por via da industrialização difusa a alargar-se progressivamente por algumas áreas rurais.

A investigação elaborada pelo CEDRU (1996) realça a litoralização do povoamento e a bipolarização da rede urbana em torno das duas áreas metropolitanas (Lisboa e Porto), com importantes movimentos intra-metropolitanos de população e actividades. Após o que identifica um conjunto de unidades urbanas de média dimensão inseridas em processos diferenciados: no litoral estão a configurar-se pequenas conurbações, acompanhado de formas de urbanização difusa, em algumas situações, em que o "urbano" e o "rural" evoluem conseguindo manter uma articulação relativamente equilibrada. Enquanto no interior do país se tem registado um processo de evolução do crescimento urbano por sucção do espaço rural envolvente. Estas e outras fragilidades são igualmente registadas por Baptista (1995), entre as quais realça a ausência de centros intermédios, isto é, entre as duas grandes aglomerações urbanas (Lisboa e Porto) e os centros que se posicionam no segundo escalão de dimensão (cerca de 100000 habitantes: Funchal, Coimbra e Braga $)^{4}$. A par de uma excessiva litoralização, tanto da orla ocidental (que concentra $85 \%$ da população urbana do país) como do Algarve. Encontra ainda o mesmo autor deficiências ao nível das acessibilidades locais e regionais e perfis funcionais concorrentes, e não complementares, ao nível sub-regional; o que não deixa de estar associado a custos de conexão inter- urbana demasiado elevados, isto é, a uma debilidade na articulação entre rede urbana e sistema de acessibilidades. Realidade esta que tem persistido na interior do país.

Nuno Soares (1998) elabora uma sistematização do sistema urbano nacional ao longo de um século, dando a conhecer as suas características de tendência longa. É detectada uma assinalável macro-estabilidade do sistema urbano nacional, coerência esta de longo prazo que é suportada em flutuações e variações dinâmicas de curto prazo. A sua estrutura manteve-se praticamente constante ao longo de cem anos no que se refere tanto ao seu perfil hierárquico como à distribuição

\footnotetext{
' Preferimos a expressão sistema urbano ao seu sinónimo de armadura urbana, também frequentemente utilizada em estudos desta natureza; a primeira expressão apresenta maior clareza e abrangência, acrescentando com vantagem à segunda conotações de dinâmica, coerência e sinergia. 2 Referimo-nos a caracterizações bastante detalhadas e rigorosas, umas adoptando perspectivas mais próximas dos pressupostos do modelo hierárquico de Christaller (Gaspar e Jensen-Butler, 1992), outras, pelo contrário, sublinhando as dimensões mais relacionadas com estruturas organizadas em rede (Baptista, 1995; CEDRU, 1996; DGOTDU/Quaternaire-Portugal, 1997); a que se segue a caracterização do sistema nacional no período de um século de Nuno Soares, 1998.

3 As cidades médias à escala de Portugal variam normalmente entre dimensões demográficas dos 20000 aos 100000 habitantes.

4 João Ferrão nota que, de acordo com um quadro publicado em Pumain, Rozemblat e Moriconi-Ebrard (1996:284) se verifica que Portugal possui, em 1990, o índice de primazia (relação entre a população das duas maiores cidades) mais baixo de entre os 15 países europeus aí contabilizados mas, pelo contrário, o índice de macrocefalia (intensidade da descontinuidade entre a população das duas maiores aglomerações e as que se lhe seguem) mais elevado: 9,1 contra, por exemplo, 7,4 em França (o segundo valor mais alto), 1,6 na Holanda e 1,5 na Alemanha (Rozenblat e Moriconi-Ebrard, citado em J. Ferrão, 1997, "Rede Urbana Instrumento de Equidade, Coesão e Desenvolvimento?", CES, Colóquio «As Políticas das Cidades», p. 40).
} 
espacial $^{5}$. No decurso desse longo período a taxa de urbanização passou de 31,8\% em 1890, para $63,5 \%$ em 1991, ou seja, de aproximadamente 1,5 milhões para 5,9 milhões de habitantes, seguindo um ritmo evolutivo de características moderadas e constantes. E extraem-se os seguintes elementos caracterizadores: até aos anos 40 do século passado existiu um tipo de crescimento urbano que privilegiava quer as unidades urbanas em torno de Lisboa e do Porto, quer igualmente outras isoladas em regiões do interior onde o incremento da indústria em determinados períodos temporais e a exploração mineira (caso da Covilhã) ou da actividade agrícola (Ponte de Sôr, por exemplo) terá fomentado a concentração de população. No período posterior à Segunda Guerra Mundial assiste-se a uma selectividade regional no processo de crescimento urbano, configurando-se as regiões de Lisboa e do Porto como efectivas regiões de cidades por oposição ao restante território, onde quando muito se verifica um diminuto e esparso número de unidades urbanas com acréscimos demográficos ${ }^{6}$.

Em 1890, a rede urbana nacional encontrava-se já perfeitamente definida em termos espaciais, havendo a registar nos anos 40 e 50, do século XX, uma organização espacial que reflecte novas especificidades económicas e que aproveita naturalmente o padrão já existente, com reforço das duas maiores áreas urbanas e, principalmente, do crescimento das unidades urbanas já existentes ao longo da faixa urbana oeste-atlântica e sul-atlântica ${ }^{7}$.
No interior do país, sobre um pano de fundo de unidades urbanas estabilizadas ou em decréscimo demográfico, sobressaem algumas cidades relativamente importantes à escala regional - muitas delas antigas sedes de Província ou de Distrito - das quais se destacam Beja, Bragança, Castelo Branco, Covilhã, Évora, Fundão, Gouveia e Portalegre. Estas cidades, devido ao relativo afastamento entre si e a alguns problemas de acessibilidade que ainda persistem, não constituem no seu conjunto efectivamente uma estrutura urbana complexa e contínua como a que se verifica no litoral. No entanto, é da maior relevância o seu protagonismo no quadro global de interioridade onde se localizam ${ }^{8}$.

$\mathrm{Na}$ figura 1 estão representadas as alterações de ordem ocorridas no conjunto das cinquenta maiores unidades urbanas do país ${ }^{9}$. No período compreendido entre 1890 e 1991 as duas maiores unidades urbanas mantêm a sua posição relativa, não havendo entre elas efectiva competição devido à existência de um diferencial populacional notório e relativamente constante. A terceira unidade urbana em 1890 correspondia à cidade de Braga, que veio a perder dois lugares na ordem urbana, ocupando hoje a quinta posição. Actualmente o terceiro lugar é ocupado pela cidade da Amadora. Coimbra mantém a sua já tradicional quarta posição. A cidade da Covilhã, que em 1890 ocupava a oitava posição, situa-se hoje na vigésima oitava.

\footnotetext{
${ }^{5}$ Cf. Nuno Soares (1998), O Sistema Urbano Nacional, tese de doutoramento, p. 194 e sgs. Esta pesquisa teve por objecto o estudo do sistema urbano nacional entre 1890 e 1991.

${ }^{6}$ Estas duas grandes regiões de cidades tendem, aliás, a deixar de ser duas regiões separadas, para passarem a ser parte integrante da «grande região de cidades» da faixa Atlântica entre a foz do rio Sado e a foz do rio Minho, que se prolongará naturalmente para norte pelo litoral da Galiza.

7 As cidades de Lisboa e do Porto mantêm a sua posição cimeira, seguidas por uma terceira cidade relativamente pequena, que variou ao longo do tempo - 1890, Braga; 1900, Braga; 1911, Braga; 1920, Coimbra; 1930, Setúbal; 1940, Setúbal; 1950, Coimbra; 1960, Coimbra; 1970, Coimbra; 1981, Amadora; 1991, Amadora - e por um vastíssimo conjunto de médias e pequenas cidades.

${ }^{8}$ A faixa interior do país contém um conjunto de urbes com importância histórica, económica e cultural, e que apresentam um perfil evolutivo de tipo rápido ou moderado, formando assim uma espécie de coluna dorsal deste vasto território interior. Nomeadamente com um perfil evolutivo rápido: Bragança, Macedo de Cavaleiros, Mirandela, Guarda, Castelo Branco e Évora; com um perfil moderado: Mogadouro, Figueira de Castelo Rodrigo, Covilhã, Fundão, Portalegre, Borba e Beja.

9 A designação "conjunto das maiores unidades em 1890" comporta, neste caso particular, as 50 maiores unidades urbanas que possuem valores de população compreendidos entre 300964 habitantes habitantes, em Lisboa, e os 6014 habitantes de Vila Real.
} 
Figura 1 - Variação de ordem das cinquenta maiores unidades urbanas, entre 1890 e 1991

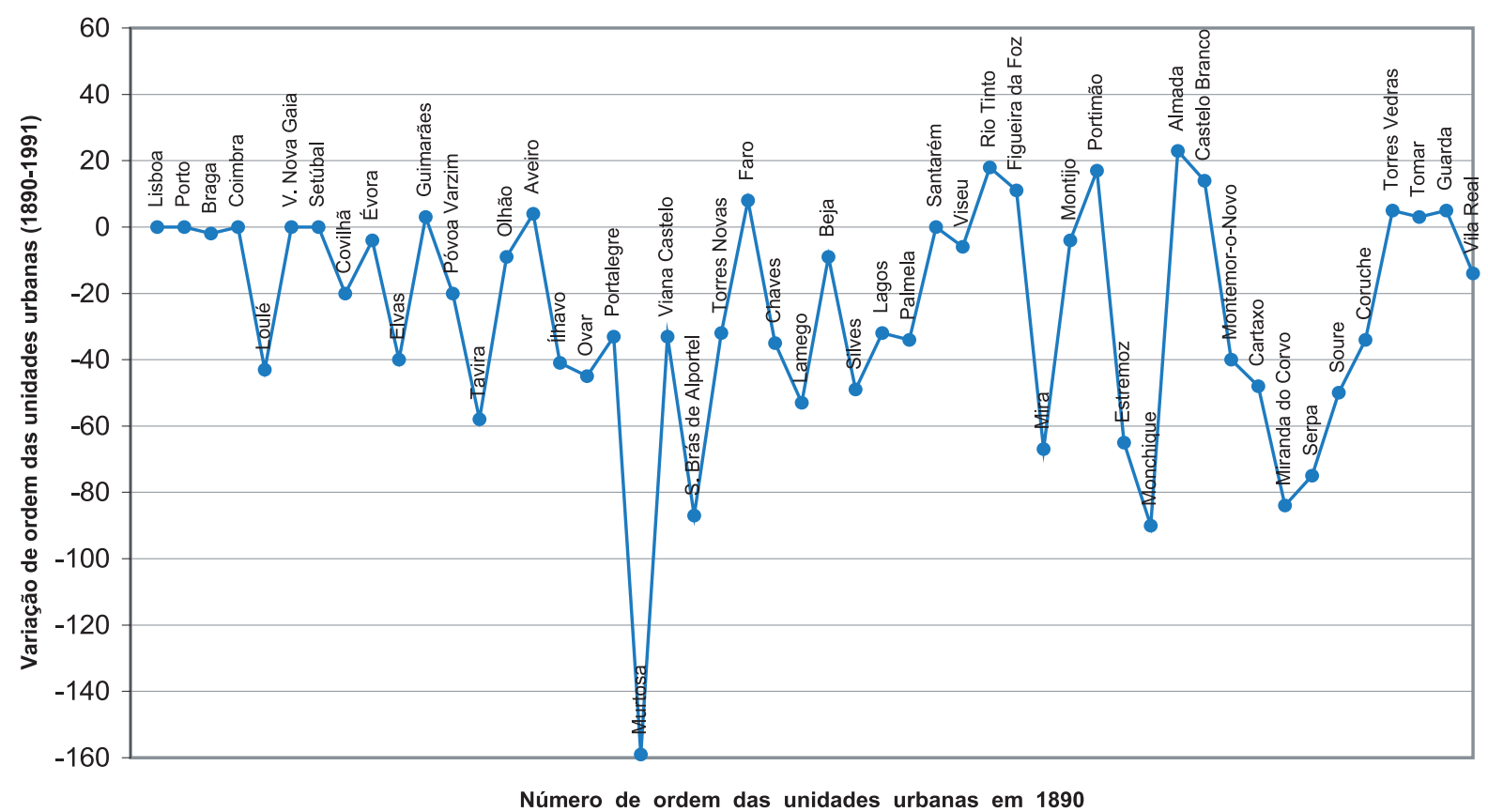

Fonte: N. Soares, 1998

Complementarmente, uma observação mais detalhada revela-nos aspectos bastante interessantes. Observemos, por exemplo, o que ocorre no conjunto das vinte maiores unidades urbanas de 1890 - Quadro 1. Deste conjunto, só cinco unidades urbanas - Lisboa, Porto, Coimbra, Vila Nova de Gaia e Setúbal - conservam, no decurso de cem anos, a sua posição hierárquica, denotando uma efectiva estabilidade. As cidades de Guimarães e Aveiro são neste contexto as únicas que ganham posição. As restantes treze são afectadas por perdas importantes de posição que oscilam entre $-44 \%$ e $-860 \%$. Sendo a perda de posição da Covilhã da ordem de $-250 \%$. 
Quadro 1 - Variação de posição entre 1890 e 1991 das vinte maiores cidades

\begin{tabular}{lccc}
\hline Unidades Urbanas & Ranking de $\mathbf{1 8 9 0}$ & Ranking de $\mathbf{1 9 9 1}$ & Variação (\%) \\
\hline Lisboa & 1 & 1 & 0 \\
Porto & 2 & 2 & 0 \\
Braga & 3 & 5 & -67 \\
Coimbra & 4 & 4 & 0 \\
Loulé & 5 & 48 & -860 \\
Vila Nova de Gaia & 6 & 6 & 0 \\
Setúbal & 7 & 7 & 0 \\
Covilhã & 8 & 28 & -250 \\
Évora & 9 & 13 & -44 \\
Elvas & 10 & 50 & -400 \\
Guimarães & 11 & 8 & 27 \\
Póvoa de Varzim & 12 & 32 & -167 \\
Tavira & 13 & 71 & -446 \\
Olhão & 14 & 23 & -64 \\
Aveiro & 15 & 11 & 27 \\
Ílhavo & 16 & 57 & -256 \\
Ovar & 17 & 62 & -264 \\
Portalegre & 18 & 51 & -183 \\
Murtosa & 19 & 178 & -837 \\
Viana do Castelo & 20 & 53 & -165 \\
\hline
\end{tabular}

Fonte: N. Soares, 1998

Em 1991, o conjunto das maiores vinte unidades urbanas ${ }^{10}$ apresenta dois tipos diferenciados de realidade: por um lado, algumas cidades importantes registam na envolvente próxima a presença de pequenas unidades urbanas predominantemente em perda de posição hierárquica, como sejam os casos de Coimbra ou do conjunto algarvio constituído por Faro, Albufeira e Portimão, que conseguem polarizar todas as restantes unidades urbanas desta região meridional. Por outro, e em relação às cidades de Lisboa e Porto e ao conjunto das unidades urbanas que as envolvem, verifica-se um outro fenómeno: as unidades urbanas próximas registam fortes ganhos de posição, enquanto outras unidades urbanas um pouco mais afastadas evidenciam variação de sentido contrário. No território interior prevalecem pequenas unidades urbanas em perda de posição, a par de algumas unidades estáveis. Na região
Centro as poucas excepções são Castelo Branco, Fundão, Guarda, Seia e Oliveira do Hospital. A Covilhã sofreu uma importante perda de posição (por registar declínio industrial), a par de outras unidades urbanas de média dimensão localizadas também na faixa interior ${ }^{11}$.

O trabalho realizado pela DGOTDU/ /Quaternaire-Portugal (1997) teve a oportunidade de aprofundar o conhecimento e a sistematização desta realidade. Procurando alternativas à tradicional visão espacial litoral-interior mas sem, todavia, assumir expressamente qualquer outro modelo, é admitido pelos autores que a sua investigação é parcialmente inspirada no conhecido "modelo do arquipélago", que nos remete para uma imagem sugestiva onde, frente a um litoral emerso - urbano e desenvolvido -, se dispõe um amplo espaço submerso - rural e deprimido -, pontualmente com um pequeno

\footnotetext{
${ }^{10}$ Lisboa, Porto, Amadora, Coimbra, Braga, Vila Nova de Gaia, Setúbal, Guimarães, Odivelas, Barreiro, Aveiro, Amora, Oeiras, Évora, Rio Tinto, Faro, Almada, Leiria, Ermesinde e Portimão.

${ }^{11}$ Chaves, Portalegre, Elvas, Estremoz, Évora e Beja.
} 
conjunto de "ilhas urbanas" que constituem o "arquipélago"12. É uma imagem original que sintetiza o sistema urbano nacional nos seus aspectos mais fortes: uma longa faixa de urbanização litoral, só interrompida no litoral alentejano, em plena fase de colmatação intersticial do espaço compreendido entre as duas áreas metropolitanas. O "arquipélago" de "ilhas urbanas", no qual podemos identificar diferentes grupos de "ilhas" - os também designados subsistemas -, apresenta algumas "ilhas" a uma cota zero ou ainda submersas.

Na parte final desse trabalho é apresentado um cenário prospectivo, do qual reproduzimos, parcialmente, o respectivo quadro de referência conceptual:

"EIXO DE CIDADES: conjunto de dois ou mais centros urbanos, com uma distribuição espacial linear, não implicando necessariamente continuidade física urbana, que assumem ou pressupõem lógicas de organização espacial complementares e concertadas, geradoras de sinergias e externalidades, e que articulam um território de proximidade comum. REDE DE CIDADES: conjunto de três ou mais centros urbanos, com uma distribuição espacial próxima e não linear, que potencialmente poderão desenvolver lógicas de organização espacial complementares e concertadas, geradoras de sinergias e externalidades. SUBSISTEMA DE CIDADES: rede de centros urbanos com lógicas de organização espacial concertadas e complementares, assumidas e enraizadas. PÓLOS DE REDES INTERNACIONAIS: cidades com tecidos institucionais e empresariais inseridos em redes ou espaços de relacionamento internacional. CIDADE-PORTA: cidade com forte relacionamento internacional, com acesso a redes de transferência de know-how e de inovação, inseridos em espaços potenciadores de competitividade ou que assumem posição importante em segmentos de mercado internacionais, envolvendo nestes processos o território que polarizam. CIDADE-ÂNCORA: cidade dinâmica, solidária com o território que estrutura, estabelecendo-se uma simbiose entre os processos de desenvolvimento urbano indutores de dinâmicas territoriais e capacidades catalisadoras de recursos regionais" (DGOTDU/Quaternaire-Portugal, 1997: 417-418).

Este cenário prospectivo é concebido a partir de diversas leituras temáticas do território e do conjunto das cidades, bem como da sua inserção no sistema urbano europeu. A sua construção baseia-se num conjunto de princípios gerais, como sejam:

- assumir as cidades como centros estruturadores e indutores de desenvolvimento de territórios alargados - cidade-âncora;

- atribuir às cidades o protagonismo de processos de internacionalização urbanos e territoriais - cidade-porta:

- reforçar lógicas de articulação e de concertação urbana face a lógicas de hierarquização de centros urbanos;

- incorporar vectores estratégicos induzidos por dinâmicas de relacionamento transfronteiriço;

- definir um Sistema Urbano Nacional integrando os sistemas urbanos que estruturam espaços regionais com lógicas de desenvolvimento convergentes;

- assegurar a inversão das actuais tendências de desagregação do espaço nacional e, simultaneamente, apostar na integração das dinâmicas urbanas nas lógicas de organização de espaços concertados e em redes ao nível europeu.

É realizada, assim, uma partição do sistema urbano nacional em diversos segmentos urbanos regionais e estes em subsistemas, redes e eixos de cidades. Ao eixo Guarda - Covilhã - Fundão - Castelo Branco, em formação, caberia estruturar e polarizar um sistema de cidades no território que abrange a Raia Central e a Serra da Estrela, eventualmente extensível às cidades de Seia, Gouveia e Pinhel, podendo assumir-se como fundamental para o reequilibro do território do interior.

Numa perspectiva mais operativa o estudo da Quaternaire-Portugal enfatiza a necessidade de

\footnotetext{
12 Este modelo tem sido divulgado por João Ferrão como proposta exploratória alternativa à tradicional visão litoral-interior.
} 
conceber políticas urbanas que incluam quatro dimensões de intervenção, complementares entre si e reforçando-se reciprocamente: uma dimensão intra-urbana (combate aos domínios problema e vulnerabilidades de cada cidade); uma dimensão inter-urbana (consolidação de subsistemas policêntricos através do reforço de fluxos, relacionamentos e acções de concertação e cooperação); uma dimensão urbano-regional (intensificação dos processos de integração das cidades e dos subsistemas urbanos nas respectivas áreas envolventes) e, por último, uma dimensão de internacionalização (promoção de melhores condições de internacionalização e visibilidade externa).

As perspectivas de evolução da rede urbana nacional não deixarão de ser determinadas pelas dinâmicas de transformação estrutural da sociedade portuguesa. De entre os principais factores estruturais sintetizados a partir de Baptista (1995), podem assinalar-se ${ }^{13}$ :

- os aspectos que se ligam com a dinâmica demográfica: acréscimos significativos nas áreas com valores negativos na componente natural do crescimento; acentuação dos índices de envelhecimento demográfico; uma continuação dos movimentos migratórios e um continuado despovoamento rural;

- os aspectos associados à terciarização da economia, à revalorização dos novos factores de localização industrial, ao impacte das novas acessibilidades e mobilidades e diversificadas percepções das distâncias, de que resulta um reforço do papel dos elementos qualitativos (qualificação da força de trabalho, do ambiente urbano, inserção das cidades nas redes urbanas, etc.);

- a integração europeia e a abertura a novos países (sobretudo a leste), que influenciam adicionais níveis de competitividade e originam estratégias empresariais que impõem maiores exigências na qualificação das estruturas urbanas na captação de investimentos e eventos;

- finalmente, as transformações da estrutura económica nacional. Embora num cenário de maior concorrência, Portugal poderá continuar a beneficiar da deslocalização de segmentos produtivos de tecnologias intermédias, ao mesmo tempo que irão reestruturar-se importantes segmentos produtivos intensivos em mão-de-obra de baixas qualificações - caso do sector têxtil.

Deste modo, e tendo em conta a integração nos sistemas peninsular e europeu, colocam-se vários desafios ao sistema urbano nacional, dos quais se podem destacar os seguintes, tendo em conta a realidade das cidades médias portuguesas ${ }^{14}$ :

- "o nível de desempenho do sistema urbano e das acessibilidades que o suportam" e a "conquista de maior centralidade" na economia europeia;

- "a dinamização dos centros urbanos localizados em áreas de 'perda', enquanto última oportunidade para manter social e economicamente activas as regiões mais desfavorecidas do país" e a criação e consolidação de redes de cidades do interior, procurando uma maior interacção e conexão através da melhoria de redes de transportes;

- a promoção de "redes de cooperação transfronteiriça", procurando aproveitar as acessibilidades do país ao exterior, que poderá ser benéfica principalmente para as cidades do interior e para a afirmação de dinâmicas emergentes, principalmente após a consolidação dos já referidos eixos de cidades.

\footnotetext{
13 Cf. Baptista, J. Mendes (1995), "Rede urbana nacional: problemas, dinâmicas, perspectivas", SEALOT/MPAT: Ciclo de Colóquios, A Política Urbana e o Ordenamento do Território, Lisboa, p. 31.

${ }^{14}$ Estes elementos caracterizadores são extraídos do Plano Nacional de Desenvolvimento Económico e Social (PNDES, 1998). Consultada a edição em CD-ROOM.
} 


\section{Das Margens para o Centro}

A região Centro constitui-se, sem dúvida, como o paradigma do que atrás dissemos. É no seu conjunto um espaço onde as dinâmicas locais e regionais de urbanização e industrialização assumem contornos que reflectem uma imagem elucidativa da própria dinâmica social e económica do país, nomeadamente no que se refere aos processos de despovoamento do interior e de concentração no litoral, quer da população, quer das actividades.

Das várias cidades existentes nesta significativa parcela do território português (cerca de um quarto deste) nenhuma ultrapassa os cem mil habitantes, ou seja, os critérios internacionalmente aceites para serem consideradas cidades médias. Mas não podemos negar que existem cidades com impacte regional considerável, independentemente da sua dimensão demográfica, o que vem sugerir que aqueles critérios são, por si só, insuficientes e, eventualmente, pouco aplicáveis e significativos face às especificidades de cada território ${ }^{15}$. Estas cidades têm uma dimensão semelhante numa perspectiva nacional e a forma de organização territorial desta região pode caracterizar-se pelo seu policentrismo (Figura 2).

Figura 2 - Dimensão das cidades da região centro

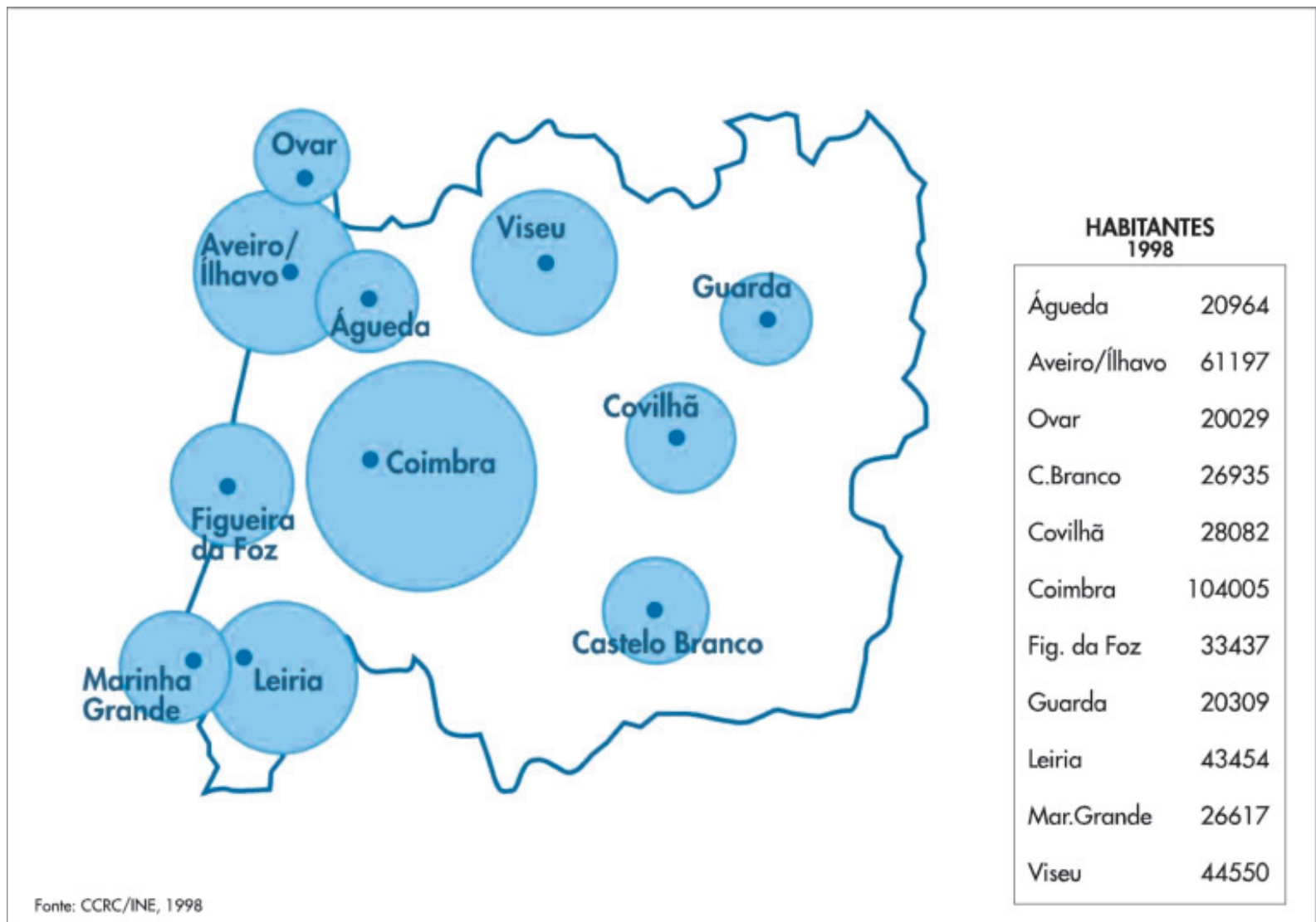
${ }_{15}$ É exactamente este desajustamento que justifica que as escalas de análise sejam não apenas novas/alternativas como também adaptadas aos
contextos a que se aplicam. 
Com base em Reis (1998), podemos afirmar que a região centro é estruturada por cinco subsistemas territoriais urbanos:

- o sistema urbano da Beira Interior (a ligação Castelo Branco - Fundão - Covilhã - Belmonte - Guarda);

- a constelação urbana centrada em Viseu e que inclui as cidades de Mangualde, S. Pedro do Sul, Nelas e Tondela, entre outras;

- o sistema Aveiro - Ílhavo - Albergaria - Águeda - Oliveira do Bairro;

- o eixo Coimbra - Figueira da Foz (que pode incluir, também, Lousã, Cantanhede e Mealhada);

- o eixo Leiria - Marinha Grande.

A cidade da Covilhã integra o primeiro subsistema urbano mencionado, no qual ocupa uma posição central, em termos geográficos. Todavia, este "eixo" não se encontra consolidado, possuindo desde logo alguns estrangulamentos que o colocam mais como uma tendência do que uma realidade concreta. Efectivamente, a ainda fraca acessibilidade interna, acrescida de uma falta de coesão da respectiva estrutura produtiva, não tem contribuído para a progressiva consolidação de um mercado regional, resultando uma interacção urbana não muito consistente. É importante salientar que, em termos históricos, nunca se terá caminhado no sentido de consolidar este subsistema urbano. Acrescente-se que cada uma destas cidades tem uma área envolvente com pequenos centros (geralmente sedes de concelho) e espaços de características rurais que têm forte ligação a essas cidades e aglomerados urbanos, quer seja pelo trabalho, quer seja pelo consumo ou para usufruir de certos equipamentos e serviços colectivos. No entanto, este conjunto de centros urbanos poderá conter bastantes virtudes no sentido de potenciar complementaridades entre eles, na criação de uma massa crítica urbana que permitiria outra escala de intervenção e, bem assim, o que não é menos importante, no reforço efectivo de uma identidade urbana/local e regional - que, ao contrário de algum senso comum, não são incompatíveis - que muito pode contribuir para o desenvolvimento destes territórios.

Mas, sublinhe-se, o interior é mais desfavorecido e, assim, o sistema urbano em que se insere a Covilhã apresenta uma certa desvantagem pela distância ao litoral e certamente pela sua interioridade. Além disso, existe uma certa fragilidade destes centros urbanos portugueses face a algumas cidades de maior dimensão do lado espanhol. No entanto, a forma de encarar a interioridade tem vindo a mudar e a ser repensada de modo diferente. Com a difusão da informação e o enorme acréscimo da mobilidade que não cessam de crescer, tem-se registado uma modificação dos horizontes espaciais de referência. É assim que o interior deve ser visto "mais como uma problemática do que como um espaço concreto de um país que numa escala ibérica ou europeia é todo ele marcado por uma forte litoralidade" (PNDES,1998).

Mas não ignoramos que muitos dos problemas existentes são já recorrentes, sendo alguns deles de natureza estrutural e, por isso, dificilmente se poderão resolver e inverter no médio prazo ${ }^{16}$. Mas o interior, como qualquer outro território, "é um espaço com pontos fortes e fragilidades, ao qual se abrem novas oportunidades e sobre o qual pesam ameaças". A observação das tendências recentes não são as melhores e os desafios que defronta não serão menores: "criar emprego e qualificar os recursos humanos"; "promover a inovação e a iniciativa empresarial"; "fomentar a integração territorial e o relacionamento institucional"; "promover a qualidade urbana global"; e rendibilizar os "recursos endógenos do território" e as "condições materiais e imateriais" nele existentes.

Deste modo, requer-se uma nova concepção dos territórios interiores para inspirar as políticas de desenvolvimento, que para serem eficazes não devem considerar estes territórios como "espaços marginais a cargo do país", mas sim como espaços de oportunidades. Estas oportunidades devem ser procuradas nos "recursos do território", nos "recursos humanos" e nos "recursos do conhecimento", e podem ser potenciadas por um novo quadro estratégico, baseado no espaço ibérico e nas grandes vias estruturais de internacionalização do território nacional e caracterizado pelas novas condições de competitividade que são potenciadas pelas novas tecnologias de comunicação e informação.

\footnotetext{
${ }_{16}$ Como a desertificação humana: diminuição da população e despovoamento das aldeias.
} 
Por tudo isto, tem sentido reconceptualizar a implementação de políticas. Por um lado, acompanhar as políticas centradas nas infra-estruturas e equipamentos com políticas centradas no «conhecimento», na «qualificação» e na «organização»; por outro, passando da fase de dispersão e especialização dos equipamentos para uma visão de ordenamento e funcionalidade. Em segundo lugar, os sistemas urbanos territoriais devem ser assumidos como o elemento estratégico do desenvolvimento, enquanto forma de organizar a concentração, de promover economias de aglomeração, de consolidar factores (avançados) de competitividade e de dar coerência aos espaços de influência das cidades.

É que actualmente as políticas de desenvolvimento regional tendem a recentrar-se nas cidades "confundindo-se as políticas de promoção da competitividade dos territórios com a promoção do sistema urbano" (Reis, 1998), tendo em consideração as infra-estruturas, o conhecimento, o ambiente e as funções urbanas.

As potencialidades do território da Beira Interior ${ }^{17}$ para desenvolver vantagens comparativas com o restante espaço nacional consistem, exactamente, em poder desempenhar um papel de charneira entre o litoral português e o interior da Extremadura Espanhola/Castilla - Léon. Para isso terá que se equipar e estruturar para garantir os serviços necessários à fixação de população, dando-lhe uma consistência de território com capacidade de sobrevivência a prazo e equilibrando dessa forma o povoamento da região Centro no seu todo. Esta ideia complementa a perspectiva defendida pela $\mathrm{CCRC}^{18}$, ao ser revalorizada a introdução da dimensão transfronteiriça na organização e estruturação do território interior. E assim sairá reforçado o sistema urbano do interior, ao mesmo tempo que o litoral da região Centro ganha uma nova frente de desenvolvimento: a Europa terrestre via interior e Espanha.
De contrário, existe a convicção de que sem esta consideração transfronteiriça se correria o risco do reforço natural de um sistema urbano nacional cada vez mais litoralizado com o inevitável acentuar das assimetrias territoriais.

No entanto, a ideia de uma rede urbana transfronteiriça é apenas isso mesmo, uma ideia, que está ainda longe de ser uma realidade ${ }^{19}$. As relações com a Espanha fazem-se ainda de forma muito pontual. Além das acessibilidades físicas, a cooperação ainda não existe enquanto tal, salvo algumas raras excepções. E sem "pontes" humanas serão difícil o reconhecimento mútuo e a cooperação com contactos permanentes e fluxos de comunicação. Mas o terreno é "fértil" para escolas e universidades. Através de intercâmbios, trocas de estudantes e cursos que juntem portugueses e espanhóis. Então a capacidade de multiplicar relações e construir uma verdadeira rede transfronteiriça não será só potencial. E a efectivar-se poderá fortalecer a articulação do eixo centro-interior com o seu congénere espanhol: Zamora - Salamanca - Cáceres.

O espaço transfronteiriço está em estruturação e as instituições locais podem aí desenvolver estratégias e acções de relacionamento, ao nível político, empresarial e institucional (Universidades, associações empresariais e culturais, etc.). A Covilhã, e área directamente envolvente, têm aí um papel particular, apoiado na qualidade e reforço da promoção de um património singular (natural, arqueologia industrial e cultural), como centro de inovação e internacionalização, com acrescida visibilidade e capacidade de atracção de capital externo.

Nesta perspectiva é decisivo, além de regenerar e qualificar, promover a inserção da cidade da Covilhã no sistema urbano regional e, bem assim, no nacional e no ibérico.

\footnotetext{
17 Doravante, quando nos referimos à Beira Interior consideram-se os concelhos dos distritos da Guarda e de Castelo Branco que constituem as Nomenclaturas de Unidades Territoriais de Nível III, da Beira Interior Norte (Almeida, Celorico da Beira, Figueira de Castelo Rodrigo, Guarda, Meda, Pinhel, Trancoso, Manteigas e Sabugal), Cova da Beira (Belmonte, Covilhã e Fundão) e Beira Interior Sul (Castelo Branco, Idanha-a-Nova, Penamacor e Vila Velha de Ródão).

18 Defendida no documento da CCRC de 1998, que preconiza o reforço da rede entre as cidades médias da região Centro, numa lógica de cinco sistemas territoriais urbanos como forma de superar a ausência de uma grande cidade.

19 As conclusões de um recente estudo sociológico são sintomáticas: a "perpetuação de uma 'fronteira de cortiça', que mantém a insonorização e que, ao impedir a passagem da comunicação, abafa as relações entre as zonas fronteiriças, que são as regiões menos desenvolvidas de Portugal e Espanha"; essa barreira apenas é atenuada com questões concretas, como o aproveitamento conjunto de hospitais ou outros equipamentos das cidades de fronteira, pois recolhe opiniões favoráveis de mais de $50 \%$ dos inquiridos (cf. estudo do sociólogo espanhol Amando de Miguel, 1999, editado pela Fundação Afonso Henriques, Zamora).
} 


\section{Policentrismo, Novas Urbanidades e Novos Desafios}

Admite-se que em áreas de baixa densidade populacional e de emprego, a cooperação interurbana se torna mesmo imprescindível para, fundamentalmente, aumentar a "massa urbana" e apostar numa rede urbana forte, capaz de contrariar as dinâmicas regressivas e conseguir atrair investimentos e pessoas. Acresce que neste tipo de territórios as cidades não devem ser vistas sem se considerarem as respectivas conexões com os aglomerados rurais. O desenvolvimento regional ganha em se enfatizar a partir de conjuntos territoriais integrados e solidários, onde se dê a osmose entre os modos de vida rurais e urbanos e, neste contexto, o quadro territorial definido pelos principais centros urbanos da região constitui uma matriz multipolarizadora do desenvolvimento numa perspectiva de valorização das periferias rurais ${ }^{20}$. Existe uma interpenetração entre espaços rurais e urbanos, não devendo perder-se de vista uma visão de equidade e de exigência de solidariedade no desenvolvimento. Mas essa complementaridade só será possível com estratégias viradas para as zonas mais desfavorecidas (em despovoamento), que devem ser articuladas com as acções em torno das cidades.

Ao mesmo tempo enfatizamos o facto de enquadrar cada cidade no contexto regional significar conceber o território regional como um sistema urbano policêntrico. E, sobretudo, pensar que o papel de cada centro urbano não é reduzir-lhe importância ou limitar-lhe a estruturação por estratégias de absorção do que lhe está mais ou menos próximo. O papel de cada cidade, e certamente da Covilhã, no sistema urbano regional é o de contribuir para consolidar o seu policentrismo e o de valorizar os pontos de articulação do conjunto do sistema. É, assim, nesta lógica que um sistema urbano bem organizado do ponto de vista intra-regional ganha sentido.

Se, historicamente, a Covilhã foi um centro de mono-indústria que funcionava como uma "ilha" orgânica dos lanifícios pouca integrada no tecido socioprodutivo da região, na actualidade está a ganhar novos dinamismos para o que contribuem novos factores de representatividade urbana (a expansão contínua da Universidade, um hospital-escola, o turismo, etc.). No centro destas mutações estão os efeitos sociais resultantes da crescente afirmação da Universidade, em cuja génese se procura aliar uma redefinição e adaptação das estratégias económicas e, a nível identitário, a sua assunção como recurso e instrumento privilegiado de reforço do poder simbólico, social e político da própria cidade. É uma capacidade emergente que está a transformar a estrutura, $o$ ambiente e as vivências urbanas, abrindo as perspectivas de um novo "modelo" urbano, o que por sua vez exige políticas urbanas adequadas e direccionadas para a recriação de um ambiente urbano atractivo e de qualidade, cuja concepção não deve "apagar" a herança histórica e cultural da Covilhã.

A morfologia, o ambiente cénico de encosta da Serra da Estrela e a organicidade do seu tecido urbano tradicional consolidado são características que fazem dela uma cidade diferente de todas as outras. Devendo aproveitar e preservar as suas panorâmicas e, bem assim, a proximidade/ligação à Serra de Estrela, como centro turístico e de lazer por excelência, que proporciona uma alta qualidade do ambiente natural ${ }^{21} . \mathrm{O}$ ambiente, o património histórico e arquitectónico, a cultura e o lazer tornam-se aspectos fundamentais da nova concepção de qualidade de vida. Deste modo, as exigências no que respeita aos equipamentos e aos elementos que enquadram o quotidiano da vida urbana passam, em grande medida, por estes domínios. É uma realidade que justifica a reavaliação dos atributos dos lugares e obriga a uma transformação das estratégias e das práticas com incidência na organização do espaço urbano.

Também as pesquisas por nós empreendidas permitiram circunscrever um imaginário sobre a Covilhã que reflecte uma deslocação da importância da indústria de lanifícios para a valorização do tecido institucional, denotando-se a configuração de uma auto-imagem diversificada na apreensão da cidade. Existem representações valorizadoras de aspectos tradicionais e outras

\footnotetext{
${ }^{20}$ Por essa razão, a articulação da Covilhã com o espaço envolvente e os centros urbanos regionais e de nível inferior, bem como com o território mais vasto em que se insere, são aspectos que não poderiam deixar de ser considerados.

${ }^{21}$ A Covilhã poderá aproveitar a visibilidade da Serra da Estrela no país, buscando força nesse nome e no conjunto de recursos que advirão não só da cidade como de toda a região.
} 
enquadradas num imaginário modernista, onde a expansão e o crescimento físico da cidade são aspectos a reter. Umas organizadas em torno de elementos históricos registados pela memória colectiva e que se constituem em pontos fortes da imagem da Covilhã, outras caracterizadas pelo seu carácter pragmático acerca das instituições locais e das representações socio-urbanísticas. Outras, ainda, singularizam a Universidade da Beira Interior nas dinâmicas urbanas, reconhecendo-lhe um papel crescente na auto-imagem e na projecção externa da cidade (D. Vaz, 2003).

Ao nível regional, a cidade da Covilhã, com a recente criação da Faculdade de Ciências da Saúde na Universidade da Beira Interior, vê reforçada a sua vocação universitária e de centro académico e cultural. Com ligações menos directas a Espanha, ao contrário de Castelo Branco (Cáceres) e Guarda (Salamanca), e mais afastada das áreas metropolitanas de Lisboa e do Porto, a Covilhã tem potencialidades para assumir aquela função qualificada no contexto do sistema urbano regional estruturante da Beira Interior.

Há um sistema urbano de escala supra-local, que representa interesses e dinâmicas emergentes, que poderá orientar-se na busca de uma representação comum e de uma estratégia de desenvolvimento regional. Por isso, cada cidade deve ser encarada também na perspectiva mais territorializada e protagonizar, em função da sua localização e especificidade, um relacionamento de cooperação com os seus territórios de proximidade.

Se considerarmos a ligação Guarda - Belmonte - Covilhã - Fundão - Castelo Branco, temos já a configuração de uma significativa constelação policêntrica, que ultrapassa no conjunto a centena de milhar de habitantes, com núcleos hoje menos distantes entre si depois da construção da A23. A Covilhã verá reforçada a sua centralidade no contexto urbano-regional, com a redução substancial do tempo das suas ligações com cada uma das extremidades desse subsistema.

O desafio que se coloca, então, à Covilhã (e demais cidades regionais) é o de criar e evidenciar as vantagens competitivas no domínio dos novos factores de localização de investimentos e de actividades que estimulem um ambiente local propício à inovação social e à iniciativa empresarial num contexto de crescente competitividade interurbana ${ }^{22}$. Neste sentido, transparece a necessidade de se desenvolverem estratégias activas, ofensivas, que promovam uma nova ideia de cidade, de um projecto de cidade, num contexto de voluntarismo selectivo e de participação dos protagonistas no espaço urbano, sejam eles públicos, associativos ou privados, institucionais ou individuais. Este esforço, para ser verdadeiramente eficaz, necessita, no entanto, de ganhar visibilidade externa. Surge, assim, a preocupação por procedimentos de marketing urbano que deverão ajustar-se à relativa especificidade que se associa às cidades de média dimensão. A construção de uma imagem de cidade enquanto lugar de atracção com determinadas vantagens locativas (acessibilidades, redes de transportes, espaço infra-estruturado, sistemas de telecomunicações, qualidade dos recursos humanos, ambiente e qualidade de vida), a par da programação de um conjunto de operações de promoção com resultados visíveis num curto período de tempo, é, justamente, o contributo resultante do recurso a técnicas de marketing urbano.

\section{Síntese Final}

A imagem da cidade da Covilhã pode sair reforçada por uma identidade "beirã" mais alargada. O que poderá conseguir-se através de uma comunicação integrada tendente a gerar envolventes favoráveis, tanto em relação às cidades da região, consideradas individualmente, como em relação à Beira Interior no seu todo. Em termos de capacidade de condicionamento do nível de decisão nacional e supra-nacional, a Beira Interior terá mais peso que as suas cidades por si só. E a sociedade da informação abre portas a um conjunto de actividades em redor das novas tecnologias de comunicação que valorizam a qualidade ambiental e não penalizam as áreas rurais e mais periféricas. Mas a comunicação territorial para ser criadora de desenvolvimento

\footnotetext{
${ }^{22}$ Não esquecendo a convicção de que é necessário entender e actuar sobre as próprias condições socioeconómicas do desenvolvimento urbano, e não apenas sobre as suas consequências ou manifestações (segregação, desemprego, reestruturação económica, especulação imobiliária, degradação ambiental...).
} 
sustentável tem que possuir traços de uma verdadeira identidade local e basear-se na difusão dos produtos locais, reais e potenciais, através das acções dos diferentes actores. A notoriedade permanente é hoje considerado um factor-chave na afirmação de um produto, de uma imagem de marca e, também, de uma cidade.

A principal preocupação das cidades médias não será a de conquistarem uma posição cimeira ou determinante nas redes urbanas em que participam mas sim a de estarem presentes em situações de visibilidade e protagonismo. E a transformação de sistemas urbanos em

\section{Referências Bibliográficas}

ALCINO, C.; DOMINGOS V.; GUEDES, P.; BRAZ, R., 1996, Projecto-piloto Urbano: para uma Cova da Beira competitiva, sistemas de informação, requalificação urbana e ambiental, Universidade da Beira Interior e agrupamento de municípios da Cova da Beira (policopiado).

ALCINO, C.; DOMINGOS V.; GUEDES, P.; BRAZ, R., 1998, Projecto Especial de Urbanismo Comercial - Centro Cívico da Covilhã, Universidade da Beira Interior, Direcção-Geral do Comércio, Câmara Municipal da Covilhã e Associação Comercial e Industrial dos Concelhos da Covilhã, Belmonte e Penamacor (policopiado).

BAPTISTA, J. M., 1995, "Rede urbana nacional: problemas, dinâmicas, perspectivas", SEALOT/MPAT: Ciclo de Colóquios, A Política Urbana e o Ordenamento do Território, Lisboa.

BAPTISTA, J. M., 1999, Políticas para o Desenvolvimento do Interior, CCRC, Coimbra.

CABRAL, M. V., 1976, O Desenvolvimento do Capitalismo em Portugal no Século XIX, A Regra do Jogo, Lisboa.

CABRAL, M. V., 1988, Portugal na Alvorada do Século XX: Forças Sociais, Poder Político e Crescimento Económico de 1890 a 1914, Editorial Presença, 2. ${ }^{a}$ Edição, Lisboa.

CEDRU, 1996, Urbanização e Coesão Social em Portugal, Lisboa (policopiado).

CES, Conselho Económico e Social, (1997), Parecer sobre a Política de Cidades, Série Pareceres e Relatórios, Lisboa.

CIDRAIS, A, 1998, O Marketing Territorial Aplicado às Cidades Médias Portuguesas: os casos de Évora e Portalegre, dissertação de Mestrado em Geografia Humana, Faculdade de Letras, U. L., Lisboa.

CCRC, Comissão de Coordenação da Região Centro, 1998, Diagnóstico Prospectivo da Região Centro, Coimbra.

Direcção-Geral do Ordenamento do Território e Desenvolvimento Urbano/ Quaternaire - Portugal, 1997, instrumentos de desenvolvimento não depende tanto das virtudes intrínsecas tomadas de per si, mas antes da capacidade política e institucional de as mobilizar de forma adequada e em tempo oportuno face às realidades existentes e aos cenários desejados.

A complementaridade entre estas cidades significa retirar benefícios da concorrência que se estabelece entre elas, superando cada uma das partes as suas desvantagens. Complementaridade e cooperação são, por isso, desafios à imaginação e à criatividade de todos os que se preocupam com os problemas urbanos.

Sistema Urbano Nacional - Cidades Médias e Dinâmicas Territoriais, Colecção Estudos 3, Lisboa.

FERRÃO, J., 1995, "Colectividades territoriais e globalização: contributos para uma nova acção estratégica de emancipação", Inforgeo, Lisboa, (9-10): 65-75.

FERRÃO, J., 1997, "Rede urbana instrumento de equidade, coesão e desenvolvimento?", CES - Conselho Económico e Social, Colóquio "A Política das Cidades», Série "Estudos e Documentos", Lisboa.

FORTUNA, C., 1997, "Destradicionalização e imagem da cidade", in Carlos Fortuna (org.) Cidade, Cultura e Globalização: Ensaios de Sociologia, Editora Celta, Oeiras.

GASPAR, Jorge e Jensen Buttler (1992), "Social, economic and cultural transformation in the portuguese urban system", International Journal of Urban and Regional Research, 16 (3): 442-461.

GUERRA, I., 2000, “O Planeamento Estratégico das Cidades", Cidades. Comunidades e Territórios, CET/ISCTE, Lisboa, (1) pp. 37-55.

Ministério do Equipamento, do Planeamento e da Administração do Território, 1998, - Secretaria de Estado do Desenvolvimento Regional, Plano Nacional de Desenvolvimento Económico e Social (PNDES), Lisboa, Dezembro (CD-ROM).

REIS, J., 1998, O Sistema Urbano da Região Centro: a posição da Comissão de Coordenação da Região Centro, online. available on.http://www.ccr-c.pt/noticias/jr/.

SOARES, N., 1998, O Sistema Urbano Português: 1890 1991, tese de Doutoramento, Universidade Nova de LisboaFCSH, Lisboa.

VAZ, D.,2003, Tempos Cruzados na Covilhã: representações urbanas e acção colectiva, tese de Doutoramento, Universidade da Beira Interior, Covilhã. 